\title{
Extraction of Chemical Warfare Agents from Soils: Case Study on O-ethyl S-2-(diisopropylamino)ethyl methylphosphonothiolate (VX)
}

\author{
Oman Zuas \\ Analytical Chemistry and Standard Division, \\ Research Centre for Chemistry-Indonesian Institute of Sciences (Pusat Penelitian Kimia-LIPI) \\ Kawasan PUSPIPTEK, Serpong 15314, Tangerang, Banten. \\ Diterima 05-10-2007 Disetujui 14-10-2008
}

\begin{abstract}
Extraction of chemical warfare agents, O-ethyl S-2-(diisopropylamino)ethyl methylphosphonothiolate (VX) in soil sample has been carried out. The extraction was performed using six different solvents including $1 \% \mathrm{TEA} / \mathrm{MeOH}$, $1 \% \mathrm{NH}_{4} \mathrm{OH} / \mathrm{MeOH}$, water $\mathrm{pH} 2$ at the ambient temperature, water $\mathrm{pH} 2$ at temperature $4^{\circ} \mathrm{C}$, water $\mathrm{pH} 7$ at ambient temperature, and water $\mathrm{pH} 7$ at temperature $4^{\circ} \mathrm{C}$. Percent recovery of $\mathrm{VX}$ in soil samples was quantitatively determined by mean LC-MS using selected reaction monitoring (SRM). Among the solvents used, water pH 2 at temperature $4^{\circ} \mathrm{C}$ gave the best extraction capability that was indicated by the highest percent recovery of VX obtained. Storing effect of spiked samples was also investigated by extracting the samples containing VX using water at $\mathrm{pH} 2 / 4^{\circ} \mathrm{C}$ and the degradation product was then identified using multiple reaction monitoring (MRM). From the study, two degradation products were identified as Bis[2-(diisopropylamino)ethyl]disulphide and ethyl methylphosphonate.
\end{abstract}

Keywords: extraction, chemical warfare agent, LC-MS, soil, VX.

\section{INTRODUCTION}

Prohibiting the development, production, stockpiling and use of chemical weapon came into force on 29 April 1997 under the Chemical Weapons Convention (CWC). For achieving the object and purpose, the convention is administrated by the Organization for the Prohibition of Chemical Weapons (OPCW) based in The Hague, The Netherlands (Söderström et al, 1996; Carrick et al, 2001). Part of this process involves the verification of chemical warfare agents, their precursors or their degradation products in samples collected from suspected production or storage sites or from the environmental in cases allegation uses (OPCW 1997). Nevertheless, in part owing to inadequate battlefield sampling and identification causing the verification of the CWA's to be often difficult (D'Agostino \& Provost 1992).

Soil has often been used as a sampling medium for verification of alleged use of CW agents and was used as a medium in an international inter-laboratory

Telp: 021-7560929, Fax: 021-7569549

E-mail:oman.zuas@yahoo.co.id comparison (Round-robin) test for the verification of chemical disarmament coordinated by the VERIFIN (Rautio 1990). The determination of CWA's in soil samples depends on effective, reliable and simple the methods of extraction. A number of works related to the extraction of $\mathrm{CW}$ agents from soil have been reported previously. Verweij \& Boter, (1976), investigated the degradation product of CWA's phosphorus containing products, while Kuitunen et al, (1991), studied the extraction of CWA's in soil samples by offline supercritical fluid extraction and capillary gas chromatography. Other studies in relation to the extraction of CWA's by solid phase extraction using different solvent have also been performed by Tornes et al, (1991a), and Tornes et al, (1991b). However, the results of these studies in less satisfactory yields mainly for soil contaminated with O-ethyl S-2(diisopropylamino)ethyl methylphosphonothiolate (VX). Groenewold et al, (1999), concluded that this phenomenon caused by the structure of VX (Figure 1) owing alkaline behaviors originating from diisopropylaminoetyl moiety to which no doubt responsible for the strongly adsorbent character and 


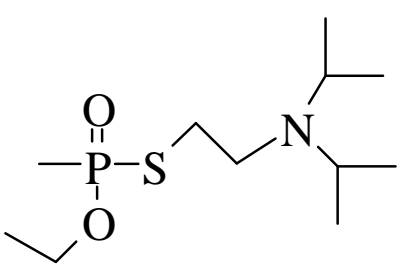

Figure 1. Structure of VX

contribute to the compound's reputation for being difficult to detect. For these reasons a study was initiated with primary objective being the method development to find how to extract the VX from soil more efficiently.

This report is based on the laboratory work focused on the extraction of VX in soil sample and identification of its degradation products. The extraction of VX was carried out based on the Finnish Institute for Verification of Chemical Weapon Convention recommended operating procedure (VERIFIN ROP) (Rautio 1994), and new method developed during the laboratory work. The VX was spiked into the soil and then the spiked soil samples were extracted. LC-MS method was employed for quantitative analysis and the results of each method were compared.

The storing effect of spiked sample before analyzed was evaluated. The spiked soil samples were stored at room temperature for 2 and 4 weeks before analysis. The best method chosen during the laboratory work was used to extract the stored sample and the results were compared. The LC-MS was employed to screen the VX degradation products.

\section{MATERIALS AND METHODS}

Soil Sample. Fine sand soil was used as a soil matrix in the study. The soil was collected from the experimental farm of the Agricultural Research Center of Finland in Jokioinen. Before use the soil was dried in air and sieved through a $2 \mathrm{~mm}$ screen to remove debris. The soil properties have been characterized by the supplier as shown in Table 1.

Chemicals. The chemicals and equipments used were provided by VERIFIN. The VX used was property of the VERIFIN laboratory and was an analytical reference standard. The VX was received and used as a $47,6 \mu \mathrm{g} / \mathrm{ml}$ (acetone) standard solution. VX, CAS No. 50782-69-9, is regulated and highly toxic compounds that must be handled in approved facilities with appropriate safety precaution to avoid risk to personnel.

All other chemicals were purchased by VERIFIN from the commercial sources: aceton (MerckDarmstadt, Germany), amoniumhydroxide (MerckDramstadt, Germany), triethylamine (Fluka chemie $\mathrm{GmbH}$, Switzerland), methanol HPLC gradient grade (J.T Baker, Holland), silylation grade acetonitrile (Piere, USA), N,O-bis(trimethylsilyl)trifluoroacetamide (BSTFA) (Pierce, USA), and formic acid (Merck-Darmstadt, Germany). Ultra high quality (UHQ) water was obtained from VERIFIN laboratory.

Equipments. The equipment used included $\mathrm{pH}$ universal paper (Macherey-Nagel, Germany), screwcapped bottles 10 and $25 \mathrm{ml}$ (Pyrex), universal centrifuge (Hettich, Germany), qualitative filter paper $90 \mathrm{~mm}$ DIAx100 circle (Whatman), disposable plastic syringe equipped dispossal filter PTFE millipore 0.45 Millex LCR (Millex, Irrish), Bond elut SCX cation exchanger (Varian, USA), sonicator Branson 3210 (Branson, Netherland), cooling system (Lauda, Wobser $\mathrm{GmbH} \& \mathrm{Co}, \mathrm{KG}$ ), and a rotary evaporator (Buchi Labortechnique, Switzerland).

The instrument for the analysis samples was the LC-MSMS (Waters, Massachusetts USA) by applying selected reaction monitoring (SRM) for quantitations of analyte and multiple reaction monitoring (MRM) for screening of degradation products. The LC conditions were as follows: a HP 1100 LC pump with a $C_{18}$ reverse phased column (Waters XTerra ${ }^{\mathrm{TM} M S}$; $150 \times 4,6 \mathrm{~mm}, 5$ $\mu \mathrm{m})$ was applied for separation of the analyte applying the isocratic elution using $80 \%$ of methanol (B eluent) of and $20 \%$ of $20 \mathrm{mM} \mathrm{NH}_{4} \mathrm{Ac} / \mathrm{pH} 8.6$ (A eluent) as eluent components. A flow rate of $1 \mathrm{ml} / \mathrm{min}$ with an injection volume $20 \mu \mathrm{l}$, was applied. A gradient elution (5-100\% (B) $/ 0-5 \mathrm{~min}+5 \mathrm{~min}$ isocratic) or isocratic elution (50\%:50\%; $A: B$ ) were used for screening of degradation products of $\mathrm{VX}$.

Table 1. Properties of fine sand soil

\begin{tabular}{lccccccccc}
\hline Soil type & $\begin{array}{c}\text { Humus } \\
(\%)\end{array}$ & $\begin{array}{c}\text { Organic } \mathrm{C} \\
(\%)\end{array}$ & $\begin{array}{c}\mathrm{pH} \\
\left(\mathrm{H}_{2} \mathrm{O}\right)\end{array}$ & $\mathrm{Ca}$ & $\mathrm{K}$ & $\mathrm{Mg}$ & $\mathrm{P}$ & $\mathrm{Na}$ & $\mathrm{S}$ \\
\hline Fine sand & 4.57 & 2.65 & 5.65 & 1565 & 123 & 60 & 31.7 & 42 & 23.6 \\
\hline
\end{tabular}


Mass spectrometric conditions were a Micromass Quattro II triple stage quadrupole mass spectrometer with positive and negative $\mathrm{APCl}$ ionization modes was used. Cone voltage $20 \mathrm{~V}$ and corona voltages $3.5 \mathrm{kV}$ and $2.0 \mathrm{kV}$ in positive mode and negative modes, respectively, were applied. Source temperature was $150^{\circ} \mathrm{C}$ and probe temperature was $450^{\circ} \mathrm{C}$. Nitrogen was used as APCl seath gas and drying gas with flow rates, $75 \mathrm{l} / \mathrm{h}$ and $350 \mathrm{l} / \mathrm{h}$, respectively. Argon was used as the collision gas with a pressure $1.0 \times 10^{-3} \mathrm{mBar}$. Collision energies applied were $15 \mathrm{eV}$. Selected reactions (SRM, MRM) for different chemicals are collected in Table 2. A quasi-molecular ion of each analyte was used as parent ion and a most intense reaction was applied for analysis. One example reaction $(\mathrm{m} / \mathrm{z} 268>128$ for $\mathrm{VX}$ ) is presented in Figure 2.

Spiking procedure. A soil sample ( $5 \mathrm{~g}$ find sand soil) was weighed into $25 \mathrm{ml}$ screw-capped glass bottle and spiked with VX at concentration level of $5 \mathrm{ppm}$. The standard solutions of VX were injected in soil that was shacked vigorously by hand and allowed to stand for $60 \mathrm{~min}$ at room temperature prior an extraction.

Extraction Procedure. Six different solvents were tested for the extraction including 1) $1 \%$ triethylamine

Table 2. Selected reaction for analysis of different chemicals

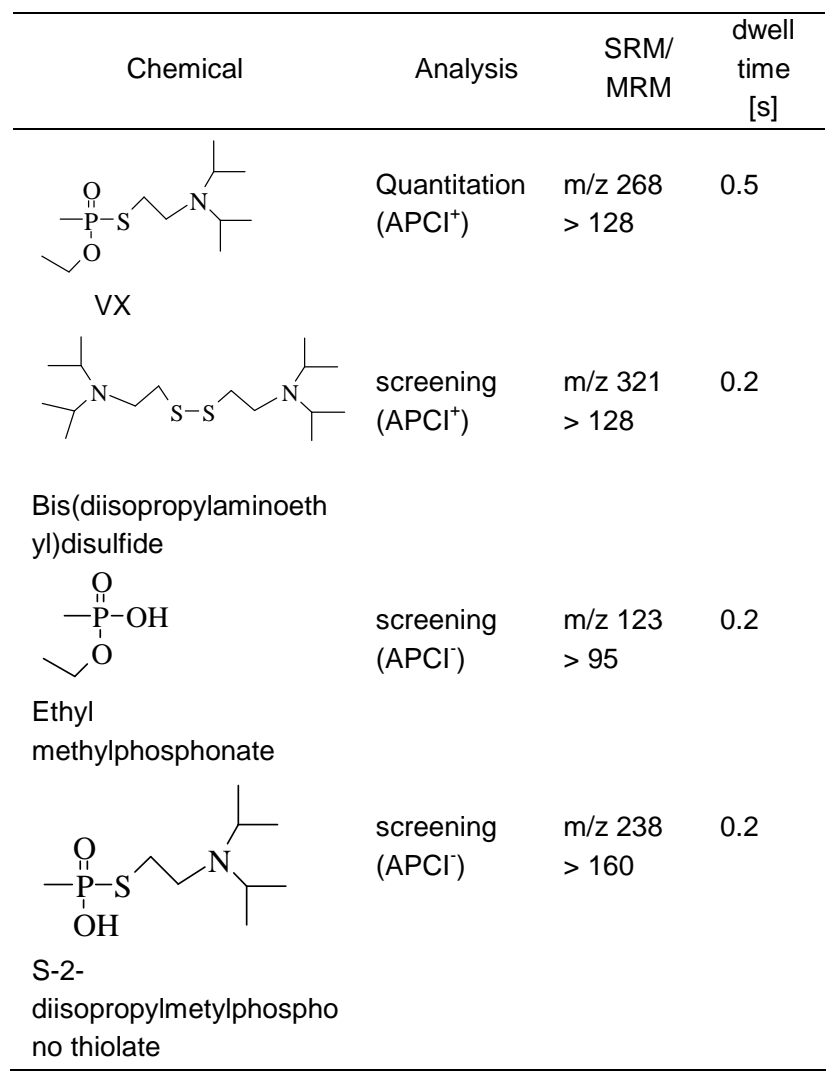

Extraction of chemical warfare agents from soils 3

in methanol (TEA/MeOH); 2) $1 \%$ ammoniumhydroxide in methanol $\left(\mathrm{NH}_{4} \mathrm{OH} / \mathrm{MeOH}\right)$; 3) water $\mathrm{pH}$ 2/ambient temperature; 4) water $\mathrm{pH} 2 / 4^{\circ} \mathrm{C}$; 5) water $\mathrm{pH}$ 7/ambient temperature; and 6) water $\mathrm{pH} 7 / 4^{\circ} \mathrm{C}$.

Three spiked soil samples and a blank were extracted in parallel with $5 \mathrm{ml}$ of each solvent using ultrasonic vibration for $10 \mathrm{~min}$ and then centrifuged for $3 \mathrm{~min}$ at $2000 \mathrm{~g}$. The supernatants were quickly filtered through Whatman No. 4 filter paper to remove particulate matter. The extraction was performed twice and then supernatant was combined into $10 \mathrm{ml}$ volumetric flask. The supernatant was filtered through disposal filter PTFE millipore 0.45 Millex LCR. The prepared extracts were stored in freezer at $-20^{\circ} \mathrm{C}$ prior to analysis. An amount of $10 \mu \mathrm{l}$ of $25 \% \mathrm{NH}_{4} \mathrm{OH}$ was introduced in $1 \mathrm{ml}$ of each water extract at $\mathrm{pH} 2$ just before analysis for tuning extract solutions alkaline.

Storing effect evaluation. Sets of spiked soil sample were stored at room temperature for 2 and 4 weeks. The samples were extracted using the best method chosen during the laboratory work. Evaluation of storing effect was made by analyzing the recoveries of VX obtained after the different storing periods and the screening of some degradation products of $\mathrm{VX}$ was performed.

\section{RESULT AND DISCUSSION}

Calibration of Quantitative Method. A set of quantitation standards were obtained by spiking the analyte in each blank extract at concentration levels of $0.05,1.0,2,5$ and 5 ppm corresponding recoveries 1 , 20,50 and $100 \%$, respectively. A typical chromatogram for blank and a standard at $0.05 \mathrm{ppm}$ and a calibration curve are presented in Figure 3.

Quantitative analysis. Over the past decade, liquid chromatography combined with mass spectrometry (LC-MS) has evolved from being primarily a research tool, available in a limited number of analytical laboratories, to a robust and widely available analytical and investigative technique. Previously concerning to this subject, a few laboratories were using LC-MS in the analysis of CWC's. This was due to a number of factors, two of which were the cost of instrumentation and a perception that the tcehnique was difficult to impement in an analytical laboratory. In the intervening years, the cost of basic LC-MS has been reduced, and the instrumentation has become robust 


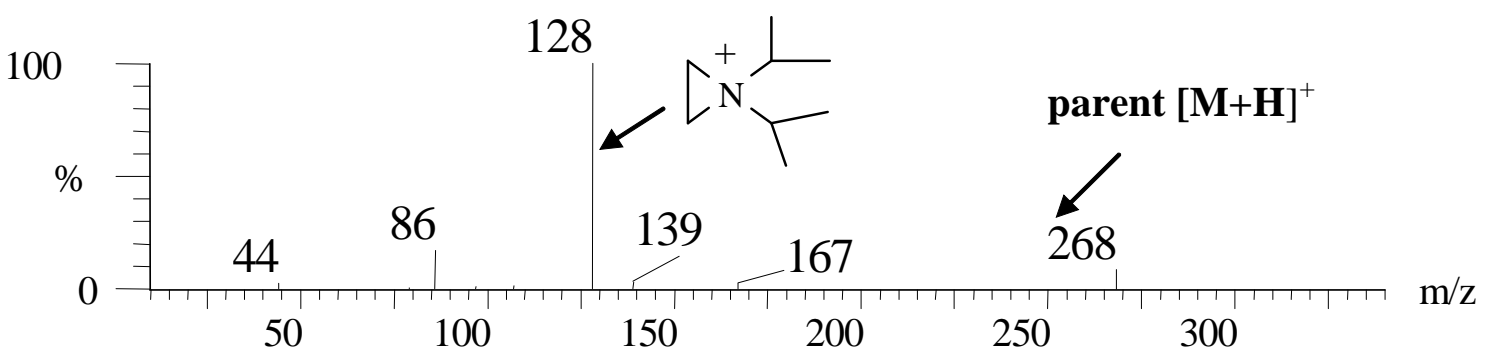

Figure 2. The LC-MSMS spectrum of VX.
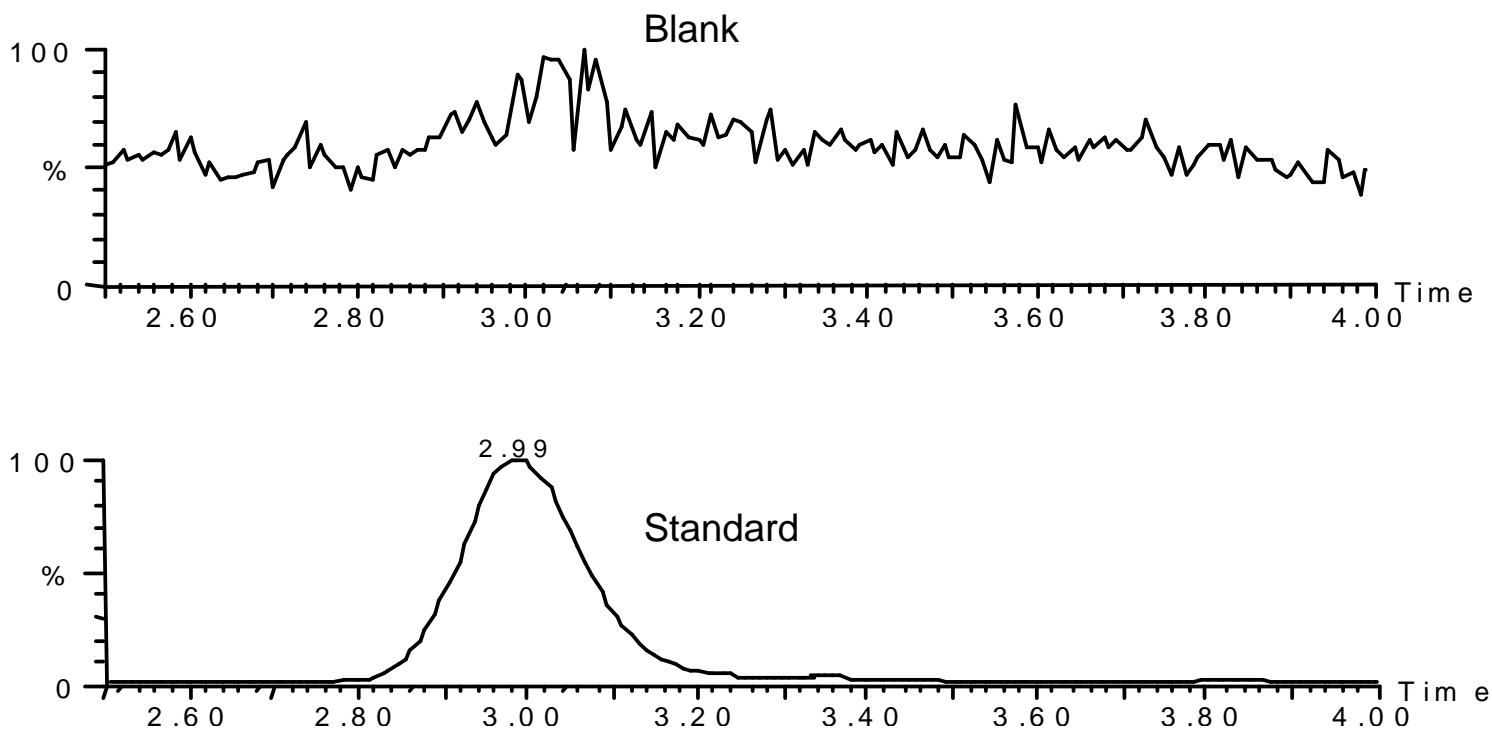

Correlation coefficient: $r=0.999923, r^{\wedge} 2=0.999846$ Calibration curve: $321426 * x+11009.4$

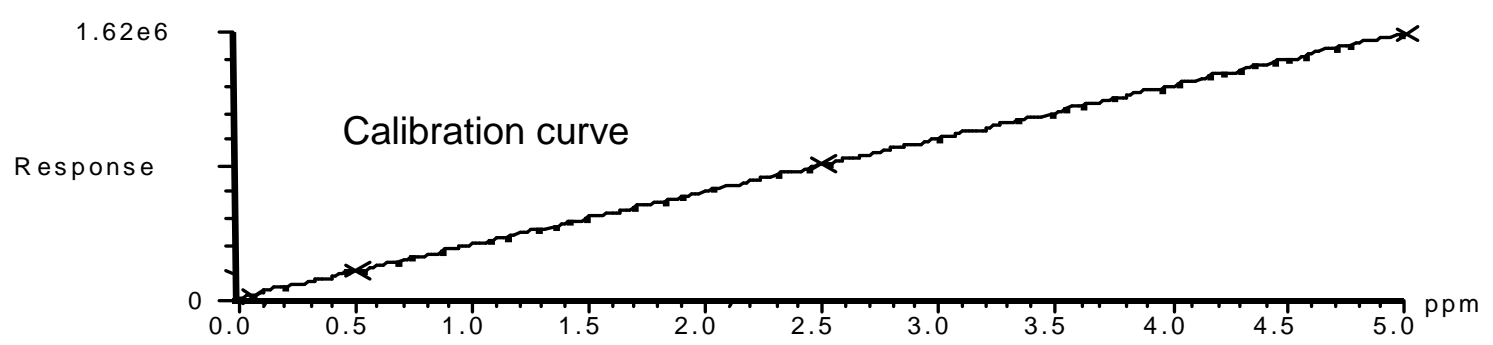

Figure 3. Calibration of LC-MS quantitation method. SRM chromatograms for blank and 0.05 ppm srandard, (A) and (B), respectively and a typical calibraton curve (C).

and easier to operate. LC-MS is now a mature technique that should be considered by all laboratories that are required to analyze chemical related to CWC's.

One of the application of LC-MS in relation to the analysis of CWC's is in identification of nerve agents for example VX and its degradation. Wils \& Hults, (1990), and Bjork, (2003), have screened and characterized the VX using LC-MS. In these two published articles, the $X V$ was reported to which the VX was extracted using solvent base such as methanol 
Table 3. Results of recoveries of VX obtained by different extraction methods

\begin{tabular}{lcccc}
\hline \multicolumn{1}{c}{ Solvent } & $\mathrm{pH}$ & $\begin{array}{c}\text { Tempera } \\
\text { ture }\end{array}$ & $\begin{array}{c}\text { Reg. } \\
\text { coeff. }\left(\mathrm{r}^{2}\right)\end{array}$ & Yield \% \\
\hline $\begin{array}{l}\text { 1\% } \\
\begin{array}{l}\text { TEA/methanol } \\
\text { (Verifin ROP } \\
\text { method) }\end{array}\end{array}$ & Alkaline & ambient & 0.999 & $51 \pm 4.8$ \\
$\begin{array}{l}1 \% \\
\mathrm{NH}_{4} \mathrm{OH} / \text { metha }\end{array}$ & Alkaline & ambient & 0.999 & $60 \pm 2.5$ \\
nol & & & & \\
$\begin{array}{l}\text { Water } \\
\text { Water }\end{array}$ & 7 & ambient & 0.991 & $30 \pm 1.2$ \\
Water & 7 & ambient & 0.998 & $47 \pm 1.9$ \\
Water & 2 & $+4^{\circ} \mathrm{C}$ & 0.999 & $31 \pm 1.9$ \\
\hline
\end{tabular}

Table 4. Effect of storing for the recovery of VX

\begin{tabular}{lcc}
\hline \multicolumn{1}{c}{ Storing time } & $\begin{array}{c}\text { Reg. Coefficient } \\
\left(r^{2}\right)\end{array}$ & Yield (\%) \\
\hline One hour & 0.999 & $58 \pm 2.6$ \\
Two weeks & 0.999 & $19 \pm 5.0$ \\
Four weeks & 0.989 & $12 \pm 3.8$ \\
\hline
\end{tabular}

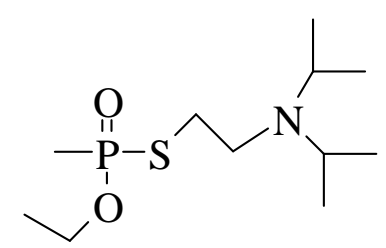

$\mathrm{pH} 7$ (neutral)

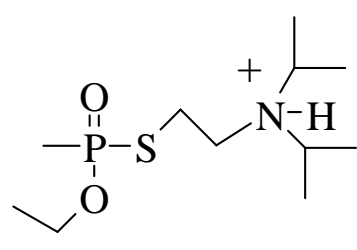

$\mathrm{pH} 2$ (ionized)
Figure 4. Structures of VX in neutral and ionized condition.
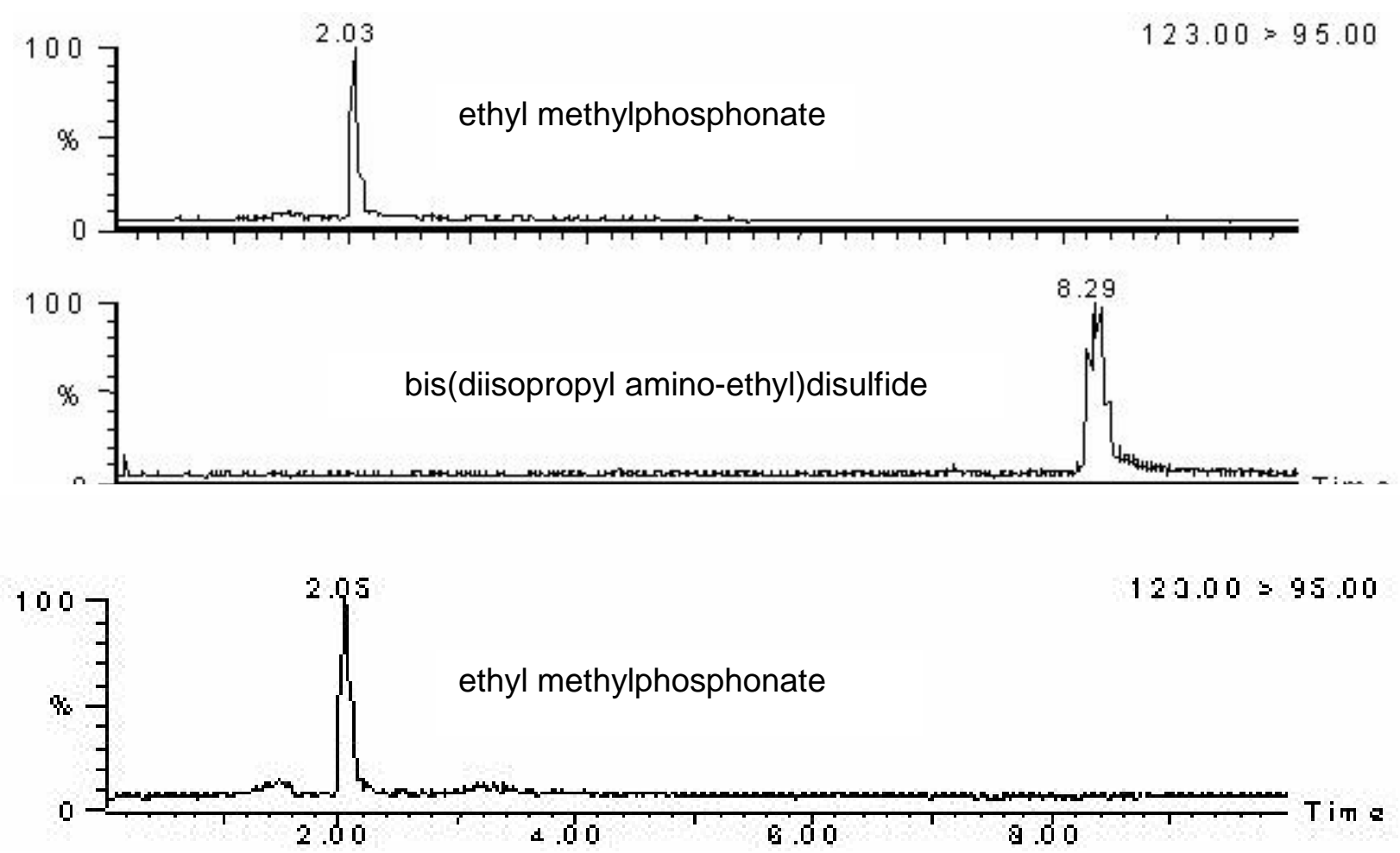

Figure 5. SRM chormatogram of degradation products of VX.

and ammonium hydroxide and its mixture at room temperatur prior to LC-MS. However, the results on these studies in less satisfactory yield. Groenewold et al, (1999), investigated that this phenomenon may caused by the structure of VX, as shown in Figure 1, owing alkaline behaviors originating from diisopropylaminoetyl moiety to which no doubt responsible for the strongly adsorbent character and contribute to the compound's reputation for being difficult to detect.
In this study, extraction of VX was investigated from soil using two different solvents (methanol and water). First the effectiveness of the methanol extraction was compared using two different modifiers: $1 \%$ TEA and $1 \% \mathrm{NH}_{4} \mathrm{OH}$. Then, the research was continued with water extractions which were performed in two different $\mathrm{pH}$ values $(\mathrm{pH} 7$ and $\mathrm{pH} 2)$ and temperatures (ambient and $+4^{\circ} \mathrm{C}$ ). The yields of $\mathrm{VX}$ from find sand soil matrix with different solvents are presented in Table 3. 
From Table 3 can be seen that ammonium hydroxide gave the best yield (60\%) that was $9 \%$ higher when the extraction is corresponded with the VERIFIN ROP method where TEA is used as the alkaline modifier of methanol. The higher recovery yield of $\mathrm{VX}$ may caused by $V X$ was more reactive in methanol than in ammonium hydroxide lead to more degradable in methanol than in ammonium hydroxide (Black \& Read 2004).

Furthermore, a recovery comparable to the VERIFIN ROP method was also obtained using cold water $\left(+4^{\circ} \mathrm{C}\right)$ as extraction solvent at $\mathrm{pH} 2$. When the temperature of the $\mathrm{pH} 2$ water was increased to ambient the recovery of $\mathrm{VX}$ was decreased $12 \%$. The same increase of temperature at $\mathrm{pH} 7$ had almost no effect for efficiency of water extraction. The decrease of $\mathrm{pH}$ in room temperature increased the recovery $17 \%$ and in $+4^{\circ} \mathrm{C}$ the increase of recovery was $27 \%$. Declaration of the effect of $\mathrm{pH}$ is obvious. The VX exists in lowered $\mathrm{pH}$ as the ionized form and is then more watersoluble than as the neutral form (see Figure 4).

Storing Effect Evaluation. Recovery of the analyte, when spiked samples were let to stand in room temperature during two or four weeks was investigated. The decrease of the yield of the analyte when spiked samples were let to stand in room temperature for two or four weeks before water extraction $/ \mathrm{pH} 2 ;+4^{\circ} \mathrm{C}$ is presented in Table 4. The recovery decreased about 40 $\%$ during the period of the first two weeks and an additional about $10 \%$ during the second two weeks.

Screening of degradation products. The screening of $\mathrm{VX}$ degradation products have been reported previously by some authors (Bjork 2003; Wils \& Hults 1990; United State \& Finland 2002). Degradation products were screened in this work from samples which were stood at room temperature two or four weeks. Three degradation products including ethyl methylphosphonate, S-2-(diisopropylamino)ethyl methylphosphonothiolate, and bis[2-(diisopropylamino) ethyl]disulfide) were screened from samples stored two weeks using LC-MS method. The degree of degradation of $\mathrm{VX}$ during the period was also estimated. The screening results are presented in Figure 5. By corresponding the height of the signal of ethyl methylphosphonate obtained from a sample with that obtained from $1 \mathrm{ppm}$ standard sample it was estimated that the portion of 1-1.5 ppm of VX had hydrolyzed during the first two weeks. S-2-(diisopropylamino)ethyl methylphosphonothiolate could not to be detected in any samples. However, there was no peak of VX could be indentified during the analysis as the SRM method was only applied for its degradation as shown in the Figure 5.

\section{CONCLUSION}

A new procedure for the identification of $\mathrm{VX}$ in soil based on cold water extraction (water $\mathrm{pH} 2$ at $4^{\circ} \mathrm{C}$ ) has been achieved. Cold water extraction of soil spiked with VX has been performed, with a result that is comparable with that of the VERIFIN ROP method (the recovery with cold water is even greater than $1 \% \mathrm{TEA} / \mathrm{MeOH}$ ). The storing effect investigation has shown the ability to extract the VX in soil samples after 4 weeks and the application of LC-MS was most useful to detect the VX in soil after cold water extraction, but not for its degradation products. Therefore, further investigation of VX degradation after cold water extraction is highly recommended.

\section{ACKNOWLEDGEMENT}

The authors are grateful thank Martin Soderstrom, VERIFIN, Helsinki University, Finland, for his generous assistance during the experiment. This work was supported by the VERIFIN Laboratory, University of Helsinki, Finland and the International Cooperation Assistance Division of the OPCW, The Hague, The Netherlands.

\section{REFERENCES}

Bjork, H. 2003. Screening and characterization of O-alkyl S-2dialkylaminoethyl alkylphosphonothiolates using LC-MS. Proceeding on International Workshop on the Analysis of Chemicals Related to the Chemical Weapons Convention. Helsinki, Finland, 8-9 September 2003.

Black, R.M. \& Read, R.W. 2004. Liquid chromatography/mass spcetometry in analysis of chemicals realted to the chemical weapon convention. In Mesilaakso, M. (ed.) Chemical Weapon Convention Chemical Analysis. Ontario:John Wiley \& Sons, Ltd

Carrick, W.A., Cooper, D.B., \& B. Muir. 2001. Retrospective identification of chemical warfare agents by high temperature automatic thermal desorption-gas chromatography-mass spectrometry. Journal of Chrom. A 925: 241-249.

D'Agostino, P.A., \& L.R. Provost. 1992. Determination of chemical warfare agents, their hydrolysis products and related compounds in soil, Journal of Chrom. A 589: 287294

Groenewold, G.S., Appelhans, A.D., Gresham, G.L., Olson, J.E., Jeffery, M., \& J.B. Wright. 1999. Analysis of VX on soil particles using ion trap secondary mass spectrometry, Journal of Anal. Chem 71: 2318-2323.

Kuitunen, M.H., Hartonen, K., \& M.L. Riekkola. 1991. Analysis of chemical warfare agents in soil samples by off-line 
supercritical fluid extraction and capillary gas chromatography. Journal of Microcol 3: 505-512.

OPCW (Organization for Prohibition of Chemical Weapon) 1997. Convention on the prohibition of the development, production, stockpiling and use of chemical weapons and on their destruction. Meeting Report, The Hague: Organization for Prohibition of Chemical Weapon.

Rautio, M. 1994. Recommended operating procedures for sampling and analysis in the verification of chemical disarmament. Helsinki: Helsinki University Press.

Rautio, M. 1990. International inter-laboratory comparison (Round-robin) test for the verification of chemical disarmament: F.1. Testing of existing procedures. Helsinki: Helsinki University Press.

Soderstrom, M.T., Bjork, H., Hakkinen, V.M.A., \& O. Kostiainen. 1996. Identification of compound relevant to the chemical weapons convention using selective gas chromatography detectors, gas chromatography-mass spectrometry and gas chromatography-Fourier transform
Extraction of chemical warfare agents from soils 7 infrared spectroscopy in an international trial proficiency test. Journal of Chrom. A 742: 191-203.

Tornes, J.A., Opstad, A.M., \& B.A. Johnsen. 1991a. Use of solid-phase extraction in determination of chemicals warfare agents: Part I. Journal of Environ. Anal. Chem 44: 209-225.

Tornes, J.A., Opstad, A.M., \& B.A. Johnsen. 1991b. Use of solid-phase extraction in determination of chemicals warfare agents: Part II, Journal of Environ. Anal. Chem 44: 227-231.

United State \& Finland. 2002. Sample preparation method for GC/MS analysis on site. Joint document, Volume 2. Meeting Report. Helsinki: VERINFIN Helsinki University.

Verweij, A., \& H.L. Boter. 1976. Degradation of S-2-Diisopropylaminoethyl O-Ethyl methylphosphonotioate in soil: Phosphorus containing products. Journal off Pest. Sci 7: 355-362.

Wils, E.R.J., \& A.G. Hults. 1990. Determination of O-Ethyl S-2diisopropylaminoethyl methylphosphonotiolate (VX) by thermospray liquid-mass spectrometry. Journal of Chrom 523: 151-161. 